\title{
ANALISIS NILAI FREKUENSI NATURAL DAN AMPLIFIKASI DESA OLAK ALEN BLITAR MENGGUNAKAN METODE MIKROTREMOR HVSR
}

\author{
Nomensen Sitorus, Singgih Purwanto, dan Widya Utama \\ Teknik Geofisika, Fakultas Teknik Sipil dan Perencanaan, Institut Teknologi Sepuluh Nopember \\ e-mail : nomensen.sitorus@gmail.com
}

\begin{abstract}
Abstrak. Mikrotremor merupakan vibrasi atau getaran tanah yang dapat disebabkan oleh sumber alam seperti angin dan gelombang laut yang berperioda panjang ataupun gangguan buatan seperti aktivitas lalu lintas, mesin pabrik, dan sebagainya. Dalam mikrotremor dikenal metode HVSR (Horizontal to Vertical Spectral Ratio). Metode HVSR biasanya digunakan pada seismik pasif (mikrotremor) tiga komponen. Metode HVSR dilakukan dengan cara estimasi rasio spektrum Fourier komponen vertikal terhadap komponen horisontal. Parameter penting yang dihasilkan dari metode HVSR adalah frekuensi natural dan amplifikasi. Kedua paramater ini dapat digunakan untuk karakterisasi geologi setempat karena parameter ini berkaitan erat dengan parameter fisik bawah permukaan. diperoleh nilai frekuensi natural Desa Olak Alen antara 1,70-10,39. Sementara itu nilai amplifikasi berkisar antara 1,3-6,2. Kemudian berdasarkan persebaran nilainya dapat dilihat bahwa hubungan antara nilai frekuensi natural dan amplifikasi adalah saling independen atau tidak berkaitan. Hal ini dikarenakan dalam nilai amplifikasi pengaruh ketebalan lapisan sedimen tidak membemberikan efek yang signifikan.

Kata Kunci: Amplifikasi; frekuensi natural; HVSR; mikrotremor.
\end{abstract}

\begin{abstract}
Mikrotremor is a vibration of the soil that can be caused by natural resources such as wind and sea waves that have long periods or artificial disturbances such as traffic activity, factory machinery, and so on. In microtremor known HVSR method (Horizontal to Vertical Spectral Ratio). The HVSR method is commonly used in passive seismic (microtremor) three components. HVSR method is done by estimating the ratio of fourier spectrum of vertical component to horizontal component. Important parameters resulting from the HVSR method are natural frequency and amplification. Both parameters can be used for local geological characterization because these parameters are closely related to the subsurface physical parameters. Obtained by natural frequency value of Olak Alen Village between 1.70 - 10.39. Meanwhile, the amplification value ranges from 1.3 to 6.2. Then based on the spread of value can be seen that the relationship between the value of natural frequency and amplification is mutually independent or not related. This is because in the amplification value the effect of sediment layer thickness does not give significant effect.
\end{abstract}

Keywords: Amplification; natural frequency; HVSR; mikrotremor.

\section{PENDAHULUAN}

Mikrotremor disebut juga vibrasi tanah dengan amplitude displacement sekitar 0,1-1 mikron dengan amplitude velocity 0,001-0,01 cm/s (Mirzaoglu dan Dykmen, 2003). Getaran ini dapat disebabkan oleh gangguan buatan seperti aktivitas lalu lintas, mesin pabrik, dan sebagainya. Dapat juga disebabkan oleh sumber alam seperti angin dan gelombang laut yang berperioda panjang. Dalam mikrotremor dikenal metode HVSR (Horizontal to Vertical Spectral Ratio). Metode ini merupakan metode yang efektif, murah dan ramah lingkungan yang dapat digunakan pada wilayah permukiman (Warnana dkk 2011). Metode HVSR biasanya digunakan pada seismik pasif (mikrotremor) tiga komponen. Nakamura menyebutkan bahwa metode HVSR untuk analisis mikrotremor bisa digunakan untuk memperoleh frekuensi natural sedimen dan ketebalan sedimen (Mufida dkk, 2013; Syaifuddin F dkk, 2016). Teknik HVSR (Horizontal to Vertical Spectral Ratio) pada analisis data mikrotremor telah digunakan secara luas untuk studi efek lokal dan mikrozonasi.

Metode HVSR dilakukan dengan cara estimasi rasio spektrum Fourier komponen vertikal terhadap komponen horisontal. Frekuensi natural setempat merupakan frekuensi pada rasio HVSR puncak pertama, sedangkan rasio HVSR pada frekuensi natural merupakan nilai amplifikasi geologi setempat 
(SESAME, 2004). Parameter penting yang dihasilkan dari metode HVSR adalah frekuensi natural dan amplifikasi. HVSR yang terukur pada tanah bertujuan untuk karakterisasi geologi setempat, frekuensi natural dan amplifikasi yang berkaitan dengan parameter fisik bawah permukaan (Herak, 2008). Amplifikasi merupakan perbesaran gelombang seismik yang terjadi akibat adanya perbedaan yang signifikan antar lapisan, dengan kata lain gelombang seismik akan mengalami perbesaran, jika merambat pada suatu medium ke medium lain yang lebih lunak dibandingkan dengan medium awal yang dilaluinya. Sementara itu frekuensi natural sangat berkaitan erat dengan ketebalan lapisan sedimennya. Karena nilai amplifikasi dan frekuensi natural merupakan dua parameter penting yang dihasilkan dari kurva HVSR maka dicari hubungan keduanya. Apakah pada daerah dengan nilai frekuensi natural yang rendah nilai amplifikasinya rendah juga atau sebaliknya.

\section{METODOLOGI}

Pengukuran mikrotremor dilakukan di Desa Olak Alen, Kecamatan Selorejo, Kabupaten Blitar. Terdapat 55 titik pengukuran yang dilakukan dengan spasi sekitar 200-300 meter. Data lapangan hasil pengukuran kemudian diolah menggunakan metode HVSR dengan alur seperti pada gambar 1.

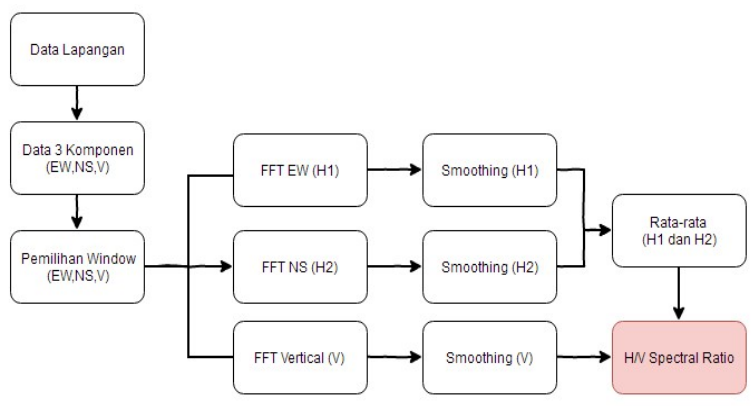

Gambar 1. Hasil olah data menggunakan metode HVSR dengan alur

Pengolahan ini bertujuan untuk mendapatkan rasio spectrum horizontal to vertical (H/V). Pengolahan data dilakukan menggunakan software EasyHVSR. Data mentah yang diperoleh dari pengukuran lapangan berupa tiga komponen sinyal dalam fungsi waktu. Kemudian ketiga sinyal tersebut dilakukan proses picking yang bertujuan untuk memilih data atau untuk menghilangkan noise yang terekam. Setelah itu dilakukan transformasi fourier (FFT) pada masing-masing komponen sinyal yang telah di picking. Dalam analisis HVSR digunakan minimal 10 window stasioner antara 20-50 detik nonoverlapping (Sesame, 2004). Pada setiap window dilakukan analisis spektrum fourier untuk mengubah domain waktu pada data mikrotremor awal menjadi domain frekuensi.

Kemudian dilakukan proses smoothing atau filtering. Smoothing dilakukan karena hasil dari proses FFT masih berupa komponen yang belum halus. Maka digunakan filter smoothing Konno dan Ohmachi dengan koefisien bandwith 40 dan cosine taper $5 \%$. Setelah proses smoothing selesai maka dilakukan penggabungan komponen horizontal dan vertikal ke dalam analisis HVSR. Selanjutnya rata-rata spektrum HVSR diplot untuk setiap titik pengukuran setelah diperoleh spektrum HVSR masing-masing window. Dari analisis HVSR akan diperoleh kurva H/V yang menunjukkan nilai frekuensi natural (f) dan amplifikasi (A). Sehingga dapat dilihat pola persebaran nilainya untuk mengetahui hubungan kedua parameter tersebut.

\section{HASIL DAN PEMBAHASAN}

Hasil pengolahan data mikrotremor dengan metode HVSR ini bersifat subjektif, oleh karena itu untuk menentukan apakah kurva $\mathrm{H} / \mathrm{V}$ tersebut sudah baik dan dapat benar benar diakui keakuratannya maka digunakan kriteria yang telah ditetapkan oleh SESAME European Research Project. Setelah diperoleh kurva $\mathrm{H} / \mathrm{V}$ yang reliable maka diperoleh nilai amplifikasi dan frekuensi naturalnya.

\section{A. Faktor Amplifikasi}

Faktor amplifikasi dipengaruhi oleh kecepatan gelombang, apabila kecepatan gelombang semakin kecil maka faktor amplifikasi semakin besar, hal ini menunjukkan bahwa faktor amplifikasi berhubungan dengan tingkat kepadatan batuan, dimana berkurangnya kepadatan batuan akan meningkatkan nilai faktor amplifikasi. Hal ini disebabkan oleh sedimen lunak yang memperlambat durasi gelombang yang menjalar di daerah tersebut, sehingga terjadi goncangan terhadap bangunan, 
begitu juga sebaliknya (Hartati, 2014). Nilai amplifikasi di Desa Olak Alen adalah 1,3 - 6,2. Berdasarkan nilai tersebut kemudian diklasifikasikan berdasarkan nilai tinggi rendahnya seperti pada tabel 1.

Tabel 1. Klasifikasi Nilai Amplifikasi (Setiawan, 2009)

\begin{tabular}{|c|c|c|c|}
\hline Zona & Klasifikasi & $\begin{array}{c}\text { Nilai Faktor } \\
\text { Amplifikasi }\end{array}$ & Lokasi \\
\hline 1 & Rendah & $\mathrm{A}<3$ & TP 1 - TP 6 \\
& & & TP 8 - TP 9 \\
& & & TP 11 \\
& & & TP 13- TP 26 \\
& & & TP 43- TP 44 \\
& & & TP 53 \\
& & & TP 55 \\
\hline 2 & Sedang & $3 \leq \mathrm{A}<6$ & TP 7 \\
& & & TP 10 \\
& & & TP 12 \\
& & & TP 27 - TP 42 - TP 50 \\
& & & TP 52 \\
& & & TP 54 \\
\hline 3 & Tinggi & $6 \leq \mathrm{A}<9$ & TP 51 \\
\hline 4 & Sangat & $\mathrm{A} \geq 9$ & - \\
& Tinggi & & \\
\hline
\end{tabular}

Berdasarkan nilai amplifikasi yang diperoleh pada setiap titik pengukuran maka dibuat peta persebaran nilai amplifikasi pada gambar 2

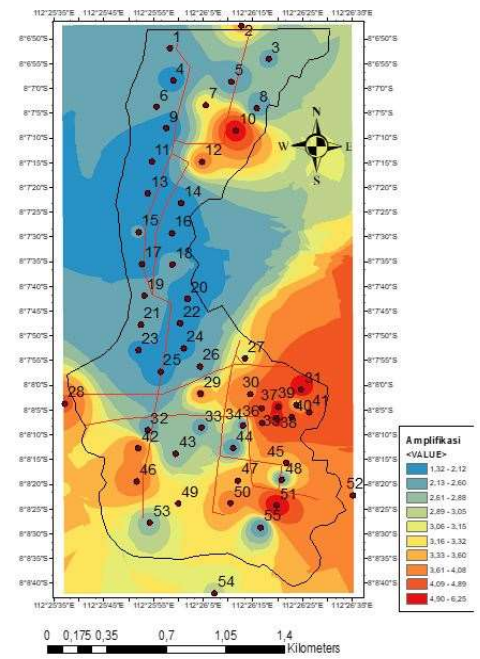

Gambar 2. Peta Persebaran nilai amplifikasi Desa Olak Alen

\section{B. Frekuensi Natural}

Frekuensi natural atau frekuensi dominan merepresentasikan banyaknya gelombang yang terjadi dalam satuan waktu. Frekuensi natural dipengaruhi oleh besarnya kecepatan rata-rata dan ketebalan sedimen bawah permukaan. Frekuensi natural berbanding terbalik dengan ketebalan sedimen (bedrock) dan berbanding lurus dengan kecepatan rata-rata. Nilai frekuensi natural suatu daerah dipengaruhi oleh ketebalan lapisan lapuk $(H)$ dan kecepatan bawah permukaan (Vs) (Mucciarelli et al, 2008). Sehingga pada daerah yang memiliki lapisan sedimen yang lebih tebal akan cenderung memiliki nilai frekuensi natural yang semakin kecil. Nilai frekuensi natural diperoleh dari sumbu horizontal puncak kurva H/V. Berdasarkan hasil pengolahan data diperoleh nilai frekuensi natural Desa Olak Alen antara 1,70 - 10,39. Maka dapat diklasifikasikan berdasarkan klasifikasi Kanai sebagai berikut:

\begin{tabular}{|c|c|c|c|}
\hline $\begin{array}{c}\text { Klasifikasi } \\
\text { Tanah }\end{array}$ & $\mathrm{Fn}(\mathrm{Hz})$ & Lokasi & Deskripsi \\
\hline Tipe IV & $6,6-20$ & - & - \\
\hline Tipe III & $4-10$ & $\begin{array}{l}\text { TP } 10 \\
\text { TP } 12\end{array}$ & $\begin{array}{l}\text { Ketebalan } \\
\text { sedimen } \\
\text { permukaan } \\
\text { kategori } \\
\text { menengah } 5 \text { - } \\
10 \text { meter }\end{array}$ \\
\hline Tipe II & $2,5-4$ & $\begin{array}{l}\text { TP } 2-\text { TP } 9 \\
\text { TP } 11 \text {, TP } 13 \\
\text { TP } 14, \text { TP } 17 \\
\text { TP } 18, \text { TP } 28 \\
\text { TP } 31 \\
\text { TP } 39 \text { - TP } 42 \\
\text { TP54 - TP } 55\end{array}$ & $\begin{array}{l}\text { Ketebalan } \\
\text { sedimen } \\
\text { permukaan } \\
\text { kategori tebal, } \\
\text { sekitar } 10-30 \\
\text { meter }\end{array}$ \\
\hline Tipe I & $<2,5$ & $\begin{array}{l}\text { TP } 1 \\
\text { TP } 15-\text { TP } 16 \\
\text { TP } 19-\text { TP } 27 \\
\text { TP } 21-\text { TP } 30 \\
\text { TP } 32-\text { TP } 38 \\
\text { TP } 43-\text { TP } 53\end{array}$ & $\begin{array}{l}\text { Ketebalan } \\
\text { sedimen } \\
\text { permukaan } \\
\text { sangat tebal > } \\
30 \text { meter }\end{array}$ \\
\hline
\end{tabular}

Dengan demikian dapat dilihat bahwa Desa Olak Alen didominasi oleh klasifikasi tanah tipe I yang berarti bahwa ketebalan sedimen permukaan di Desa Olak Alen sangat tebal > 30 meter. Hal ini didukung oleh hasil pengambilan data bor pada 2 titik di desa olak alen hingga kedalaman 30 meter dan 22 meter yang berupa pasir kelanauan. Berdasarkan nilai frekuensi natural yang diperoleh pada tiap titik pengukuran kemudian dibuat peta persebaran nilai frekuensi natural seperti pada gambar 3 . 


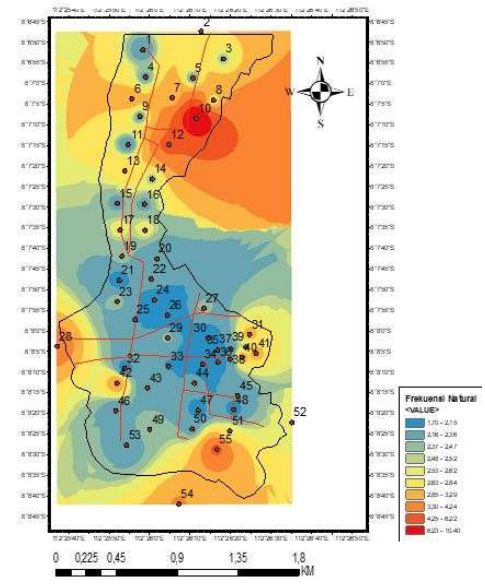

Gambar. 3. Peta Persebaran Nilai Frekuensi Natural Desa Olak Alen.

\section{Hubungan Nilai Amplifikasi dan Frekuensi Natural}

Berdasarkan persebaran nilai amplifikasi (gambar. 2) dan nilai frekuensi natural (gambar 3) Desa Olak Alen dapat dilihat bahwa hubungan keduanya cenderung berbanding terbalik. Di sebelah utara nilai amplifikasi cenderung lebih rendah sementara nilai frekuensi naturalnya cenderung lebih tinggi. Dan sebaliknya, di sebelah selatan nilai amplifikasi cenderung lebih tinggi dengan nilai frekuensi natural yang lebih rendah. Akan tetapi apabila diperhatikan lebih detail pada setiap titiknya ternyata hubungan keduanya tidak menentu atau dapat dikatakan saling independen. Hubungan nilai amplifikasi dan frekuensi natural pada setiap titik secara jelas dapat dilihat pada gambar 4. Dapat dilihat persebaran nilainya yang sangat acak. Saat frekuensi natural rendah nilai amplifikasi ada yang rendah dan ada yang tinggi begitu juga sebaliknya. Ketidak saling terkaitan kedua parameter ini dapat disebabkan oleh nilai ketebalan sedimen yang tidak terlalu berpengaruh pada nilai amplifikasi. Sementara untuk nilai frekuensi natural parameter ini merupakan salah satu faktor yang sangat berpengaruh.

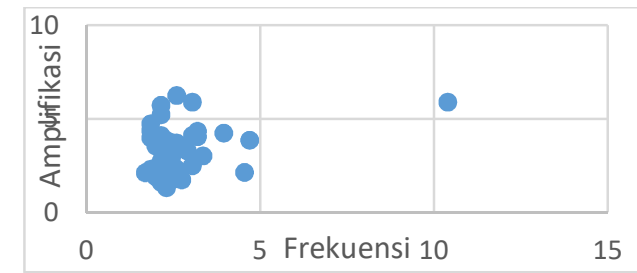

Gambar 4. Hubungan Nilai Amplifikasi dan Frekuensi Natural Desa Olak Alen.

\section{PENUTUP \\ Simpulan}

Nilai amplifikasi Desa Olak Alen berkisar antara 1,3-6,2 dengan nilai frekuensi natural 1,70-10,39. Ketebalan sedimen tidak memberikan pengaruh yang signifikan terhadap nilai amplifikasi sehingga hubungan antara nilai amplifikasi dan frekuensi natural saling independen.

\section{Saran}

Dapat dilakukan pengukuran kembali saat musim kemarau karena nilai fisis lapisan tanah yang dapat berubah dengan kondisi saat musim penghujan saat pengambilan data ini.

\section{DAFTAR PUSTAKA}

Hartati, Lidia. 2014. Pemetaan Tingkat Resiko Gempabumi Daerah Liwa dan Sekitarnya Berdasarkan Pengukuran Mikrotremor. Thesis. Yogyakarta : UGM.

Herak, M. 2008. ModelHVSR: a Matlab tool to model horizontal-to-vertical spectral ratio of ambient noise. Computers and Geosciences 34, 1514-1526

Mirzaoglu, M. and Dykmen, U. 2003. Application of Microtremor to Seismic Microzoning Procedure, Journal of The Balkan Geophysical Society, Vol.6 No.3.

Mufida, A., Santosa, B. J., \& Warnana, D. D. 2013. Inversi Mikrotremor Spektrum H/V untuk Profilling Kecepatan Gelombang Geser (Vs) Lapisan Bawah Permukaan dan Mikrozonasi Wilayah Surabaya. Teknik POMITS, 1-8.

SESAME. 2004. Guidelines For The Implementation Of The H/V Spectral Ratio Technique on Ambient Vibrations. Europe: SESAME Europen research project.

Setiawan J.R. 2009. Mikrozonasi Seismitas Daerah Yogyakarta Dan Sekitarnya. Tesis. Bandung: Institut Teknologi Bandung. Syaifuddin F, Bahri A S, Lestari W and Pandu J 2016 Microtremor study of Gunung Anyar mud volcano, Surabaya, East Java AIP Conference Proceedings 17300500042016

Syaifuddin F, Bahri A S, Lestari W and Pandu J 2016 Microtremor study of Gunung Anyar mud volcano, Surabaya, East Java AIP Conference Proceedings 1730 0500042016

Warnana, D.D., Triwulan, S. and Utama, W. (2011), "Assessment to the soil-structure resonance using microtremor analysis on pare-east Java, Indonesia", Asian Tran. Eng., 1(4), 6-12. 